Portland State University

PDXScholar

8-8-1990

\title{
A Confirmatory Factor Analysis of Two Competing Social Power Measurement Systems
}

Joseph E. Criqui

Portland State University

Follow this and additional works at: https://pdxscholar.library.pdx.edu/open_access_etds

Part of the Psychology Commons

Let us know how access to this document benefits you.

\section{Recommended Citation}

Criqui, Joseph E., "A Confirmatory Factor Analysis of Two Competing Social Power Measurement Systems" (1990). Dissertations and Theses. Paper 4168.

https://doi.org/10.15760/etd.6051

This Thesis is brought to you for free and open access. It has been accepted for inclusion in Dissertations and Theses by an authorized administrator of PDXScholar. Please contact us if we can make this document more accessible: pdxscholar@pdx.edu. 
AN ABSTRACT OF THE THESIS OF Joseph E. Criqui for the Masters of Science in Psychology presented August 8, 1990.

Title: A Confirmatory Factor Analysis of Two Competing Social Power Measurement Systems.

APPROVED BY THE MEMBERS OF THE THESIS COMMITTEE:

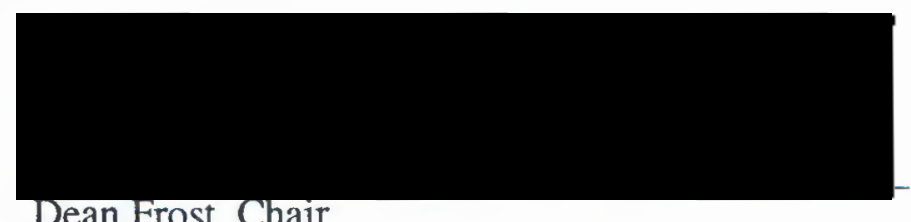

Dean Frost, Chair

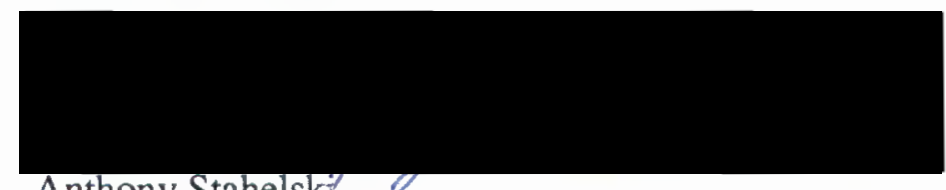

Anthony Stahelsk:

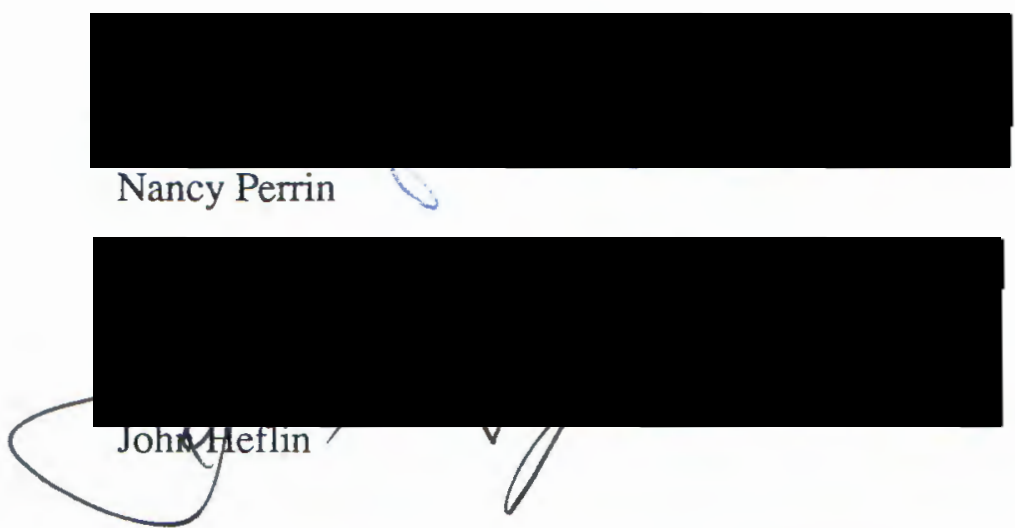

The main purpose of this study is to analyze a measurement instrument developed by Frost \& Stahelski (1988) to measure French \& Raven's (1959) bases of social power. The measurement instrument of a competing typology of social influence tactics (Kipnis, Schmidt, \& Wilkinson, 1980) was also administered to the same managerial population 
$(\mathrm{N}=108)$. Confirmatory factor analyses using LISREL (Joreskog \& Sorbom, 1986) were performed on each scale. Possible relationships between the two typologies were explored. Results include confirming a modified Frost \& Stahelski scale and no confirmation of the Kipnis et al. scale. Canonical correlation yielded two dimensions where Coercive Power and Expert Power relate to Assertiveness and Rationality respectively. Exploratory factor analysis of the composite scores from both typologies yielded two factors called Positive Power and Negative Power. Implications and future research are briefly discussed. 
A CONFIRMATORY FACTOR ANALYSIS OF TWO COMPETING SOCIAL POWER MEASUREMENT SYSTEMS

\author{
by \\ JOSEPH E. CRIQUI
}

A thesis submitted in partial fulfillment of the requirements for the degree of

MASTERS OF SCIENCE

in

PSYCHOLOGY

Portland State University

1991 
TO THE OFFICE OF GRADUATE STUDIES:

The members of the Committee approve the thesis of Joseph E. Criqui presented August 8, 1990.

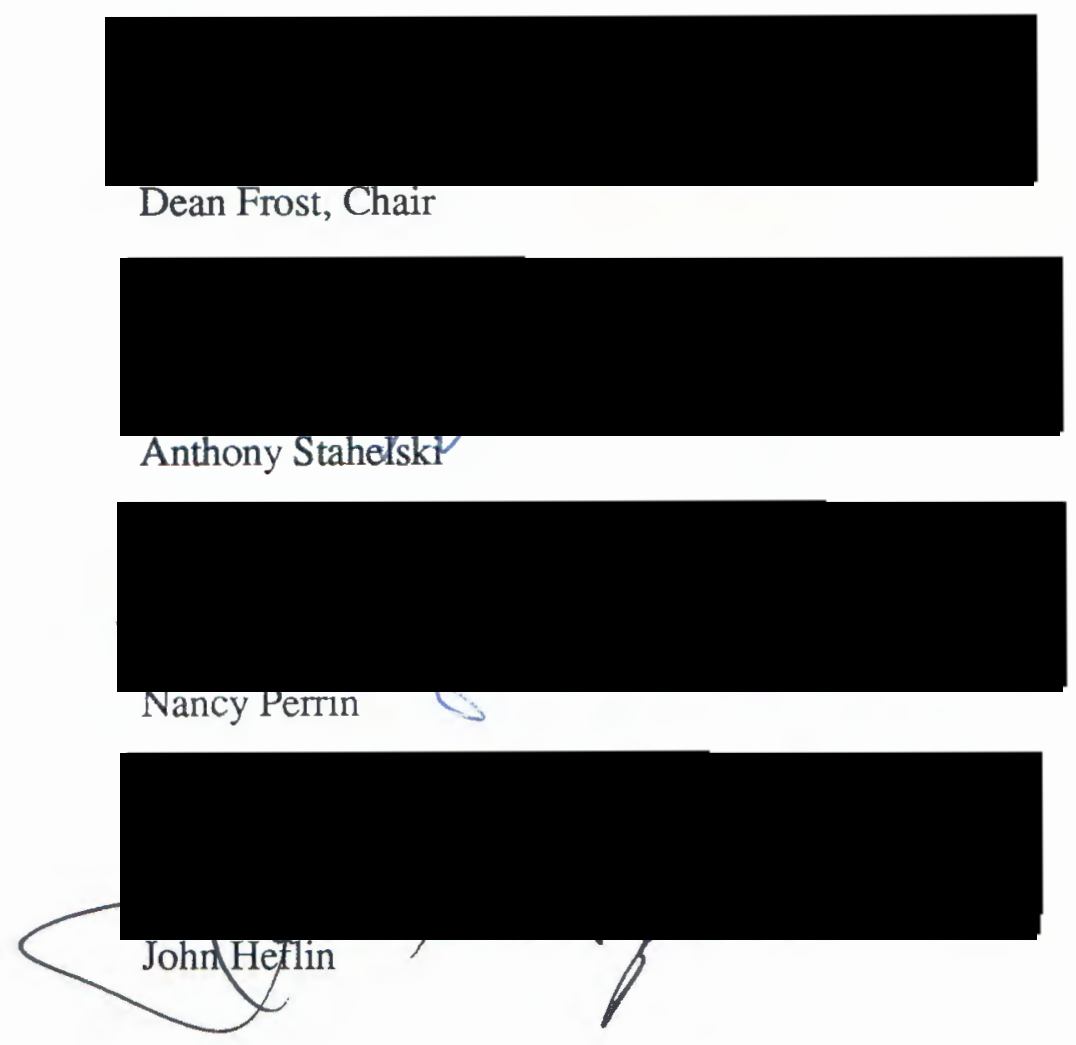

APPROVED:

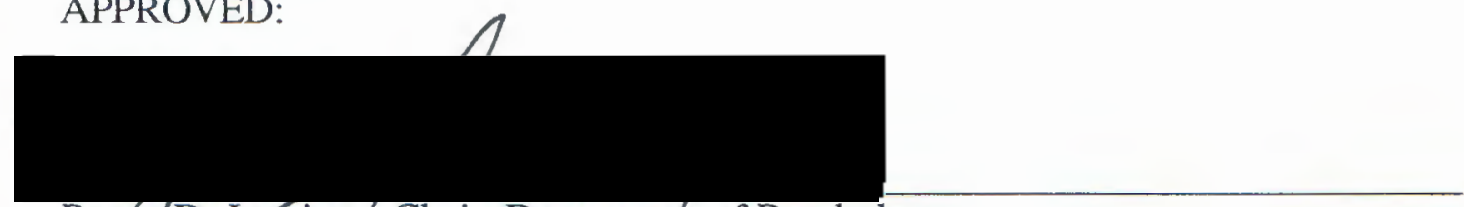

Roger D. Jenning \$, Chair, Department of Psychology

C. William Savery, Interim Vice Provost for Greduate Studies and Research 
LIST OF TABLES $\ldots \ldots \ldots \ldots \ldots \ldots \ldots \ldots \ldots \ldots$ iv

LIST OF FIGURES $\ldots \ldots \ldots \ldots \ldots \ldots \ldots \ldots \ldots \ldots \ldots$

INTRODUCTION $\ldots \ldots \ldots \ldots \ldots \ldots \ldots \ldots \ldots \ldots \ldots \ldots \ldots \ldots$

Problem Statement . . . . . . . . . . . . . . . 1

French \& Raven $\ldots \ldots \ldots \ldots \ldots \ldots \ldots \ldots \ldots \ldots \ldots$

Prior Empirical Studies $\ldots \ldots \ldots \ldots \ldots \ldots \ldots \ldots$

Recent Research $\ldots \ldots \ldots \ldots \ldots \ldots \ldots \ldots \ldots \ldots$

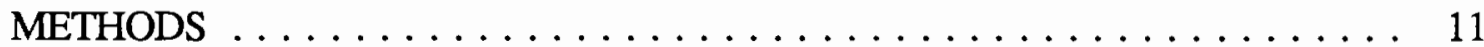

Subjects $\ldots \ldots \ldots \ldots \ldots \ldots \ldots \ldots \ldots \ldots \ldots \ldots \ldots \ldots \ldots \ldots$

Instrumentation $\ldots \ldots \ldots \ldots \ldots \ldots \ldots \ldots \ldots \ldots \ldots \ldots \ldots \ldots$

Procedure $\ldots \ldots \ldots \ldots \ldots \ldots \ldots \ldots \ldots \ldots \ldots \ldots \ldots$

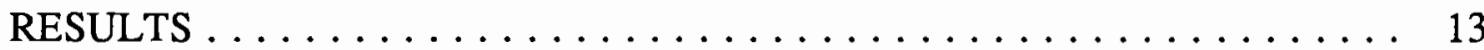

French \& Raven Scale. . . . . . . . . . . . . . . . 18

Kipnis, Schmidt, \& Wilkinson Scale . . . . . . . . . . . . 22

Combining the Two Scales $\ldots \ldots \ldots \ldots \ldots \ldots \ldots \ldots$

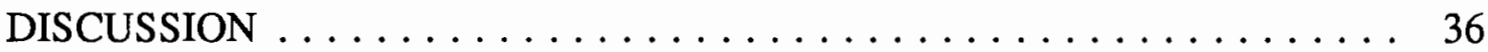

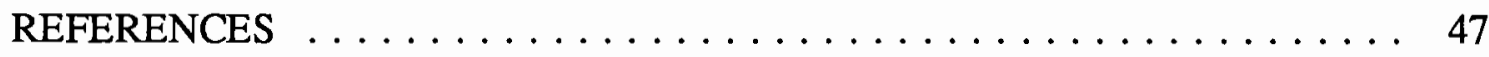




\section{LIST OF TABLES}

I Final Questionnaire Item and Sub-Scale Means and Standard

Deviations for the Frost \& Stahelski (1988) Scale . . . . . . 14

II Final Questionnaire Item and Sub-Scale Means and Standard

Deviations for the Kipnis, Schmidt, \& Wilkinson

(1980) Scale . . . . . . . . . . . . . . . 16

III Test Statistics for the Confirmatory Factor Analysis of the

French \& Raven (1959) Model . . . . . . . . . . . . 20

IV Factor Loadings for the Items Retained in the Final French \&

Raven Model . . . . . . . . . . . . . . . . 25

$\mathrm{V}$ Interfactor Correlations Between the French \& Raven Factors . . . . 26

VI Test Statistics for the Confirmatory Factor Analysis of the

Kipnis et al. (1980) Model . . . . . . . . . . . . . . . 28

VII Factor Loadings for the Exploratory Factor Analysis of the

Kipnis et al. Questionnaire Data . . . . . . . . . . . . 29

VIII Factor Intercorrelations of the Kipnis et al. Exploratory Factor

Analysis .................. 30

IX Relationship Between the French \& Raven (1959) and Kipnis et al.

(1980) Constructs . . . . . . . . . . . . . . . . . . . . 32

X Standardized Canonical Coefficients for Each Scale ....... 33

XI Factor Loadings for the Higher Order Exploratory Factor Analysis 35 


\section{LIST OF FIGURES}

FIGURE

PAGE

1. Path Diagram of the Hypothesized French \& Raven (1959) Model of Social Power . . . . . . . . . . . . . . 19

2. Path Diagram of the Final French \& Raven (1959) Model of Social Power ...................... 24

3. Path Diagram of the Hypothesized Kipnis, Schmidt, and Wilkinson (1980) Model of Social Power . . . . . . . . . . . . 27 


\section{INTRODUCTION}

\section{PROBLEM STATEMENT}

The main focus of this paper is to make advances in content validity for a scale developed to measure the social power constructs developed by French and Raven (1959). In addition, the scale used to measure the French and Raven bases of power will be compared to the scale of a competing power typology.

\section{FRENCH \& RAVEN}

The bases of social power proposed by French \& Raven (1959) have appeared in the literature for about 30 years. Numerous studies of social power/influence and leadership behavior (see Podsakoff and Schriesheim, 1985 for a comprehensive review of field studies) have used the bases of social power. French and Raven (1959) discussed general, dyadic social influence and power "limited to influence on the person, P, produced by a social agent, $\mathrm{O}$, where $\mathrm{O}$ can be either another person, a role, a norm, a group, or a part of a group" (p. 260).

To briefly define the bases of power as originally presented by French and Raven, reward power "depends on O's ability to administer positive valences and to remove or decrease negative valences" (p. 263). Coercive power "stems from the expectation on the part of $\mathrm{P}$ that he will be punished by $\mathrm{O}$ if he fails to conform to the influence attempt" (p. 263). Legitimate power is "that power which stems from internalized values in $P$ which dictate that $\mathrm{O}$ has a legitimate right to influence $\mathrm{P}$ and that $\mathrm{P}$ has an obligation to accept this influence" (p. 265). Referent power "has its basis in the identification of $\mathrm{P}$ with O. By 
identification, we mean a feeling of oneness of $\mathrm{P}$ with $\mathrm{O}$, or a desire for such an identity" (p. 266). Finally, "the strength of expert power of O/P varies with the extent of the knowledge or perception which $P$ attributes to $O$ within a given area" (p. 267).

In this paper we will be concerned with improvement of the measurement of this power typology in an organizational setting. Specifically, we'll be concerned with organizational behavior in formal, downward, relationships of a supervisor (influencing agent $\mathrm{O}$ ) and a subordinate (the influenced person $\mathrm{P}$ ) in a field setting.

\section{PRIOR EMPIRICAL STUDIES}

A recent review of the research in this area by Podsakoff and Schriesheim (1985) has produced an in depth critique of the field studies utilizing the French and Raven bases of power in organizational research. They discuss serious concerns with regard to contradictory results found across the research. Specifically, they noted contradictory findings between studies of how the French and Raven's taxonomy and the related leader reward and punishment behavior seem to affect subordinate outcome variables. For example, Szilagyi (1980) found leader reward behavior to be positively related to subordinate performance and satisfaction. However, Burke and Wilcox (1971) in a study relating French and Raven's bases of power to employee satisfaction found reward power was negatively, though not significantly, correlated with any of five satisfaction measures.

Podsakoff \& Schriesheim argue that the inconsistencies across studies may be due to inadequacies in the three most popular measurement instruments used to measure the bases of power. These instruments were developed by Bachman, Smith, \& Slesinger (1966), Student (1968), and Thamhain \& Gemmill (1974). Most importantly, they argue that all of the instruments are sorely lacking in content validity. Narrow operationalization of the 
power constructs along with the inclusion of seemingly extraneous content by these instruments seriously jeopardizes the extent to which the scales are addressing the French and Raven constructs. It is unreasonable to assume that these single item scales adequately represent the theoretical domains of the power constructs. The use of single item scales also makes it impossible to assess internal consistency as an index of reliability.

Another shortcoming of the traditional scales, according to Podsakoff and Schriesheim, is the use of an attributional referent in the wording of the items as opposed to a behavioral referent. Respondents are answering the question why do I comply (an attributional referent) rather than to report how their supervisor acts (a behavioral referent). These responses are often treated as if they were measures of perceptions of managerial behavior. They argue that people are more likely to attribute their compliance or satisfaction to the socially desirable characteristics of the supervisors knowledge (expert power) or likability (referent power) rather than to bribes (reward power) or punishment avoidance (coercive power).

Another concern they raise is that the items are so vague, it requires too much interpretation on the part of the respondents. Also they note that differential results are obtained depending upon whether a Likert scale or a rank order scale is used.

Podsakoff and Schriesheim conclude:

The purpose of this article has not been to attack studies of French and Raven's (1959) bases of social power or to imply that additional studies of social power are not needed. On the contrary. On the basis of this review, it might be argued that an adequate examination of the French and Raven conceptualization has yet to be conducted, and that much more research is badly needed in this domain. Although the French and Raven framework remains highly popular, the existing research does not support drawing confident conclusions about such things as relations between the five power bases and subordinate outcome variables. This situation is unacceptable, and it warrants and demands immediate attention to address the problems noted in this review. (p. 409)

In support of Podsakoff and Schriesheim's criticisms, Rahim (1986) empirically 
studied the Bachman, et al. (1966) and Student (1968) instruments and found little or no convergent validity, and unacceptable retest reliability coefficients for 7 of the 10 items.

Podsakoff and Schriesheim brought to light many deficiencies of past research studying French and Raven's power constructs. In spite of their review, recent research studies continue to demonstrate many of the methodological flaws they addressed.

\section{RECENT RESEARCH}

In the past, the majority of research relied heavily on two or three instruments to measure French and Raven's bases of social power. Currently, it is almost as if a new measurement instrument appears with each new study. Several recent field studies have included the study of social power in organizations.

Wexley and Snell (1987) studied the relationship of social power to the performance appraisal interview. Due to high intercorrelations among reward, expert, and referent powers, they combined them into one construct called positive power. They found managers perceived by their subordinates to be high in positive power, to be more participative and supportive, and less critical in the appraisal interview. This study used a scale developed to measure attributed power. Podsakoff and Schriesheim (1985) have warned against possible social desirability bias in responses to attributed power. In addition, as Rahim (1986) puts it "an instrument should be designed to measure the potential or enacted power bases of a superior. Whether a power base affects subordinates' compliance must be determined empirically" (p. 469).

Abdalla (1987) in a study involving the effectiveness of the social power bases as determined by supervisor/subordinate/situational attributes in the Arabian Gulf region used a modified Bachman (1968) scale. Factor analysis of the ten item scale lead to three factors of social power which are "reward-punishment influence process", "position-organization 
influence process", and "expert-referent influence process". As a predictor of the influence process, level of subordinate's education was the subordinate attribute found to have the greatest individual contribution to the variance on the three influence processes. Superiors expertise was an important supervisor's attribute which related positively with positionorganization and expert-referent processes. Finally, analysis of job attributes found the degree of job enrichment positively related to position-organization and expert-referent processes.

Abdalla's ultimate goal was to determine the extent to which his findings support previous findings and therefore generalize to another culture. He determined that his study substantiates some findings of previous research and does not substantiate others. Abdalla asserts that the explanation for discrepancies with previous research may be due to geographical differences. This may be true but cannot be tested confidently without a valid measurement instrument to apply to both settings. The problems surrounding the Bachman instrument have already been discussed.

In a correlational field study, Fiorelli (1988) studied the use of the five bases of social power in interdisciplinary clinical teams. Some of the disciplines represented were medicine, nursing, psychology, audiology, and others responsible for creating physical therapy treatment goals for individual patients. Subjects were asked to rate the individual in the group they perceived as most influential, which turned out to be the physician most of the time. Their scale was a 25 item, Likert response instrument adapted from Spekman (1979), and although he reports to have a reliability coefficient .78, some questions seem to leave too much interpretation up to the subject and call for the subject to attribute why they complied as opposed to asking about the influencer's behavior. Again, this has been discussed as a possible weaknesses of instruments of social power. His findings include expert power to be the most frequently cited individual power base and physicians most frequently seen as being able to effect the majority of decisions. Both group and individual 
reward and coercive power were found to negatively relate to productivity, and individual coercive power negatively related to participation. Power bases were also found to be related to decision making style. When respondents felt that autocratic decision making was used, less expert power and more coercive power were displayed.

The Fiorelli study is somewhat different from our present purpose in that the direction of influence attempts wasn't necessarily downward. The groups were informal in structure which may effect findings. More importantly, one first needs a valid instrument to assess if directions (ie. upward, downward, and lateral) of influence relate differentially to the power bases. In measuring the five bases of power, Fiorelli adapted a 15-item scale created by Spekman (1979) to measure attributed power which through factor analysis originally yielded four factors with a high degree of intercorrelation between them.

Another study related social power to organizational climate as measured by four orientations including Reward Orientation, Personnel Policies, MBO Orientation, and Status Organization (McDaniel, Parasuraman, \& Futrell, 1985). They used yet another scale to measure social power and found expert, referent and legitimate power to be correlated with all four of the organizational climate dimensions, where coercive power was not correlated with any. Their study was correlational and no factor analysis was performed. They used a scale based upon the procedure of Dieterly and Schneider's (1974) who did not do factor analysis and also attained high intercorrelations between power bases.

Although the present study focuses on field studies, it is interesting to note that a recent laboratory study involving the measurement of the French and Raven power constructs gives reason to suspect that some of the same shortcommings discussed this far may apply to laboratory studies also.

The effects of role, sex and attitudes on power were studied by Offermann and Schrier 
(1985). Subjects were put in the role of either subordinate or supervisor and told they had a disagreement with the other. They then rated the likelihood that they would take each of 40 actions to exercise power to influence the other person. Through factor analysis they found 8 factors which they called Reasoning, Indirect, Withdrawal, Reward/Coercion, Pressure, Unilateral, Negotiation, and Personal/Dependent. The authors retained items that loaded on multiple factors. This implies that the power constructs are correlated.

Reasoning, Negotiation, and Personal/Dependent strategies were considered most often by individuals. Significant sex effects were found on Indirect, Reward/Coercion, Negotiation, and Personal/Dependent strategies, where role effected Withdrawal, Unilateral and Negotiation strategies. Women and those in supervisory roles reported more negative attitudes toward having power than men and those in subordinate roles. Additionally, men reported more negative attitudes toward the power of others than women.

The representative items given for the Reward/Coercion factor are "offer rewards for cooperation" and "try coercion or blackmail". Instead of stating specific behaviors, these items seem to leave it up to the subject to guess or interpret what rewards or blackmail might mean to them which may or may not be the same across subjects. In addition, the items may imply informal or illegitimate influence, given that most companies won't openly condone blackmail. The same argument could be made for some of the other constructs in this scale.

Power has not only been measured as a dependent variable, but has also been used as a stimulus. Two recent studies were found that used power as an independent variable. Although they do not necessarily pertain directly to our investigation, they are worth noting.

Shaw and Condelli (1986) studied the effects of compliance outcomes on the powerholder-target relationship. They used power as part of the stimulus exposing subjects to six scenarios corresponding to the six power bases and varied the outcome of 
compliance on the target as leading to positive, negative or unknown outcomes. They found main effects for outcome in which positive outcomes "enhance P's future use of power, decrease necessity of surveillance, make $P$ more attractive to $T$, and increase T's private acceptance of P's demands" (p.240). Main effects for power bases were also found with coercive power eliciting the lowest ratings on the outcome variables. Targets were perceived as more the cause of positive rather than negative outcomes and in the unknown outcome condition, were attributed more responsibility for compliance outcome when expert, referent and informational power were used.

Another study which included gender effects related to power was done by Dovidio, Ellyson, Keating, Heltman, \& Brown (1988). They looked at visual dominance behavior in mixed sex dyads in differential power situations, using reward and expert power as the stimuli. They found differential effects for sex in visual displays of dominance while listening or speaking in the different power conditions.

It is clear from this review that methodological problems connected to the study of French and Raven's constructs continue. However, a recent systematic effort to address the measurement problems with French and Raven's power bases has been made (Frost and Stahelski, 1988; Stahelski, Frost, \& Patch, 1989).

Frost and Stahelski (1988) developed a theory driven 23 item scale of the five social bases of power through exploratory factor analysis and found these five power factors to be independent. They also showed a relationship between the power bases and the leadership behaviors Initiation of Structure and Consideration.

Stahelski, Frost and Patch (1989) administered the Frost and Stahelski instrument to college administrators at three different campuses. They found no difference in pattern of power base used at the same hierarchical level within a single industry. They found Expert and Referent powers were reported to be used most often while Coercive power was 
reported to be used least frequently. In addition, they found that as the number of subordinates increases, so does the use of coercive power.

These two studies address several concerns about the French and Raven typology raised in the past (Podsakoff and Schriesheim, 1985; Rahim, 1986). First, a behavioral referent is used in the items instead of an attributional one, reducing the problem of social desirability. Second, they avoided single item scales in an attempt to assess the whole domain of each power construct. Finally, the items were stated as simply and straightforward as possible to reduce interpretation to a minimum.

Kipnis, Schmidt, and Wilkinson (1980) have objected to the French and Raven taxonomy as not adequately covering the behavioral domain of influence possibilities. They write, "with but few exceptions, our thinking about this topic is guided by anecdotal evidence or armchair speculations that have been organized into rational classifications of power tactics" (p.440).

Kipnis et al. wanted to study upward and lateral influence as well as downward and took an inductive approach by asking people to identify situations in which the subject was successful in getting a boss, co-worker, or subordinate to do something they wanted. Through content analysis and several exploratory factor analyses, they found eight factors overall involved in influence. These are Integration, Rationality, Assertiveness, Sanction, Exchange, Upward appeal, Blocking, and Coalitions. Of these factors, five were found to be involved in downward influence which is the focus of this paper. These include Assertiveness, Sanctions, Integration, Rationality, and Coalitions.

In the present paper, the Frost and Stahelski (1988) scale and the Kipnis, et al. (1980) scale will be administered to the same population. A confirmatory factor analysis will be performed on each measurement instrument, singly. These analyses are appropriate because from the initial research and exploratory factor analyses we can now hypothesize the number of factors and what items will load on each, as well as the pattern of 
correlations among the factors. An empirical test such as this is the next logical step toward scale development and content validity. A valid and reliable instrument will lead to a reduction in the shortcomings and inconsistencies discussed previously and increase the utility of research results.

Four main analyses will be performed in this study. The specific hypotheses addressed in this study include:

1) The Frost and Stahelski (1988) scale will yield 5 independent factors in support of the French and Raven (1959) bases of power. (See page 19 for a diagram of the hypothesized factor structure.)

2) The downward influence portion of the Kipnis et al. (1980) scale will yield 5 factors corresponding to the influence strategies found by Kipnis, et al. (1980). (See page 24 for a diagram of the hypothesized factor structure.)

In addition, two exploratory analyses will be performed, these are:

3) Composite scores from the 5 French and Raven factors will be correlated with the 5 Kipnis et al. factors to determine what specific relationship may exist between them.

4) The data from both scales will be pooled and an exploratory factor analysis will be performed, to determine the underlying structure of the two scales in an effort to discover whether they are measuring the same or different constructs. 


\section{METHODS}

\section{SUBJECTS}

Subjects will be managers in a large western region utility company. They will be randomly selected from a mailing list and contacted via the company's internal mail system. Participation will be voluntary and anonymous.

\section{INSTRUMENTATION}

The 23 item measurement instrument developed by Frost and Stahelski (1988) designed to measure the five bases of social power constructs proposed by French and Raven will be used. It asks for self report frequency rating of specific behaviors exhibited in downward influence attempts.

The 57 item measurement instrument developed by Kipnis, et al. (1980) will also be administered to the same population.

\section{PROCEDURE}

The measurement instruments will be administered as part of a larger research project and will be mailed directly to managers in the organization. A cover letter and instruction sheet will be enclosed as well as the phone number of a contact person in the organization in case of questions. Subjects will be instructed to complete the questionnaires and return them to the researchers in the provided envelopes. 
The instructions read:

I am conducting research on how managers direct and influence behavior of their subordinates. As a starting point, I am attempting to operationally define and measure specific work behaviors used to influence coworker's actions. I am only interested in how often supervisors use these behaviors and ask you to please respond by circling the appropriate number indicating use of that behavior in supervising your subordinates. Remember that you are rating how you actually behave with your subordinates, not what you think is desirable or should be done. Your survey will not be seen by anyone but myself and your responses will be confidential, anonymous, and reported in group form only. I hope you will now share with me how frequently you use the following behaviors in your job as manager, supervisor, or department head. Please feel free to contact me if you have any questions about this study. Thank you for your assistance. 


\section{RESULTS}

One hundred eight questionnaires were returned and used in the analyses, which corresponds to a return rate of $18 \%$. The 17 items used for analyzing the French and Raven power constructs are a subset of the complete 23 item questionnaire. Only the 17 items retained by Frost and Stahelski (1988) after their initial exploratory factor analysis were used in this study. Their factor analysis supported the 5 factors theorized by French \& Raven (1959) with the 17 items grouping into 5 subscales; reward, coercive, legitimate, expert, and referent power. Table I contains specific items that make up each of the power base subscales, along with item and subscale means and standard deviations. Missing data were coded as a 1 (NEVER) to be consistent with the Kipnis et al. (1980) procedure.

Items used for analyzing the Kipnis et al. (1980) influence strategies are also a subset of the complete 57 item questionnaire. Kipnis et al. retained 22 items on their final downward influence scale. From these items, subscales were constructed corresponding to the influence strategies negotiation, rationality, assertiveness, sanctions, and coalitions. Table II contains specific items that constitute each influence tactic subscale along with item and subscale means and standard deviations.

Confirmatory factor analyses were performed using LISREL VI (Joreskog \& Sorbom, 1986). This analysis yields several measures of overall goodness of fit for each of the hypothesized models. These fit measures include the chi-squared statistic used to test the null hypothesis that the model fits the data. The goodness-of-fit (GFI) and adjusted goodness-of-fit (AGFI) indices are also computed to assess the overall fit of the model. Finally, the root mean square residual (RMR) measures the average residuals of the correlations predicted by the model compared to the observed correlations. 
TABLE I

FINAL QUESTIONNAIRE TTEM AND SUB-SCALE MEANS AND STANDARD DEVIATIONS FOR THE FROST \& STAHELSKI (1988) SCALE

standard

mean deviation

REWARD POWER

12.60

item results

1. Promote them or recommend them for promotion.

6. Recommend them for awards or for announcements of recognition.

10. Give them high performance ratings.

19. Give them extra time off as a reward.

item results

5. Expect that your orders and requests will be carried out because you are the boss and they will not question an order from a superior.

9. Let them know that you have a right to expect that your directions will be followed.

14. Emphasize that you probably have information that they do not have and therefore a good reason for any direct request or order.

\section{REFERENT POWER}

item results

4. Set the example and rely upon your people to follow your example.

8. Use your good relationship with them to get the job done. want to let you down. 
TABLE I

FINAL QUESTIONNAIRE ITEM AND SUB-SCALE MEANS AND STANDARD DEVIATIONS FOR THE FROST \& STAHELSKI (1988) SCALE (continued)

\section{EXPERT POWER}

item results

3. Advise and assist them.

4.21

0.76

7.* Make on -the-spot corrections.

12. Give them interesting, challenging assignments.

17. ${ }^{*}$ Give them boring routine assignments.

item results

16. Criticize them.

20. Give them extra work as punishment.

22. Recommend them for formal disciplinary action or reprimands.

*Items dropped from revised scale and final model. 


\section{TABLE II}

FINAL QUESTIONNAIRE ITEM AND SUB-SCALE MEANS AND STANDARD DEVIATIONS FOR THE KIPNIS, SCHMIDT, \& WILKINSON (1980) SCALE

mean $\begin{array}{r}\text { standard } \\ \text { deviation }\end{array}$

INGRATIATION

16.01

item results

3. Sympathized with him/her about the added problems my request has caused.

9. Acted very humbly to him or her while making my request.

17. Acted in a friendly manner prior to asking for what I wanted.

28. Made him or her feel good about me before making my

2.37

0.98 request.

44. Waited until he or she appeared in a receptive mood before $\quad 2.33$

0.86 asking.

46. Made him or her feel important ("only you have the brains, 2.63

0.96 talent to do this").

RATIONALITY

13.84

item results

13. Used logic to convince him or her.

3.65

0.88

31. Explained the reasons for my request.

4.29

0.87

38. Presented him or her with information in support of my point

3.65

0.93 of view.

40. Wrote a detailed plan that justified my ideas.

item results

11. Set a time deadline for him or her to do what I asked.

18. Demanded that he or she do what I requested.

19. Told him or her that the work must be done as ordered or he or she should propose a better way.

39. Bawled him or her out.

45. Simply ordered him or her to do what was asked. 
TABLE I

FINAL QUESTIONNAIRE ITEM AND SUB-SCALE MEANS AND STANDARD DEVIATIONS FOR THE KIPNIS, SCHMIDT, and WILKINSON (1980) SCALE

(continued)

SANCTIONS

6.96

2.89

item results

6. Threatened to give him or her an unsatisfactory performance

1.44

0.86 evaluation.

15. Promised (or gave) a salary increase.

26. Threatened his or her job security (e.g., hint of firing or getting him or her fired).

34. Threatened him or her with loss of promotion.

49. Gave no salary increase or prevented the person from getting a pay raise.

COALITIONS

item results

12. Obtained the support of co-workers to back up my request. $\quad 2.64$

32. Obtained the support of my subordinates to back up my request. 
In addition to overall fit, detailed measures of fit are computed. These measures assess specific parameters throughout the models. The detailed measures of fit used in this study include t-values, modification indices, and normalized residuals. T-values test the hypothesis that the free parameters are significantly different from zero and therefore contribute substantially to the model. Modification indices give the expected decrease in chi-square if a single constraint is freed while the rest of the model remains unchanged.

\section{FRENCH \& RAVEN SCALE}

Figure 1 represents the first model tested as specified by the first hypothesis which states that the scale developed by Frost \& Stahelski (1988) will yield 5 independent factors in support of the French \& Raven (1959) bases of social power. The hypothesized model was not supported by the confirmatory factor analysis overall (see Table III).

The chi-square test of the null hypothesis that the model fit the data is significant $(p<.0001)$, indicating that the model does not fit the data. It should be noted that chisquare "is sensitive to sample size and very sensitive to departures from multivariate normality of the observed variables" (Joreskog \& Sorbom, 1986). This sensitivity can result in an inflated chi-square statistic leading to rejection when in fact the model does fit the data. Therefore other measures of overall fit should be considered as well. For this model, GFI and AGFI also indicate poor fit, supporting the significant chi-square statistic. Finally, RMR is sizable indicating a possible specification error in the model. Inspection of the t-values indicated 3 items that did not load significantly. Two of these 3 items had the only modification indices that were unacceptably large indicaing these items wanted to load on factors other than the one they were specified to load on. 


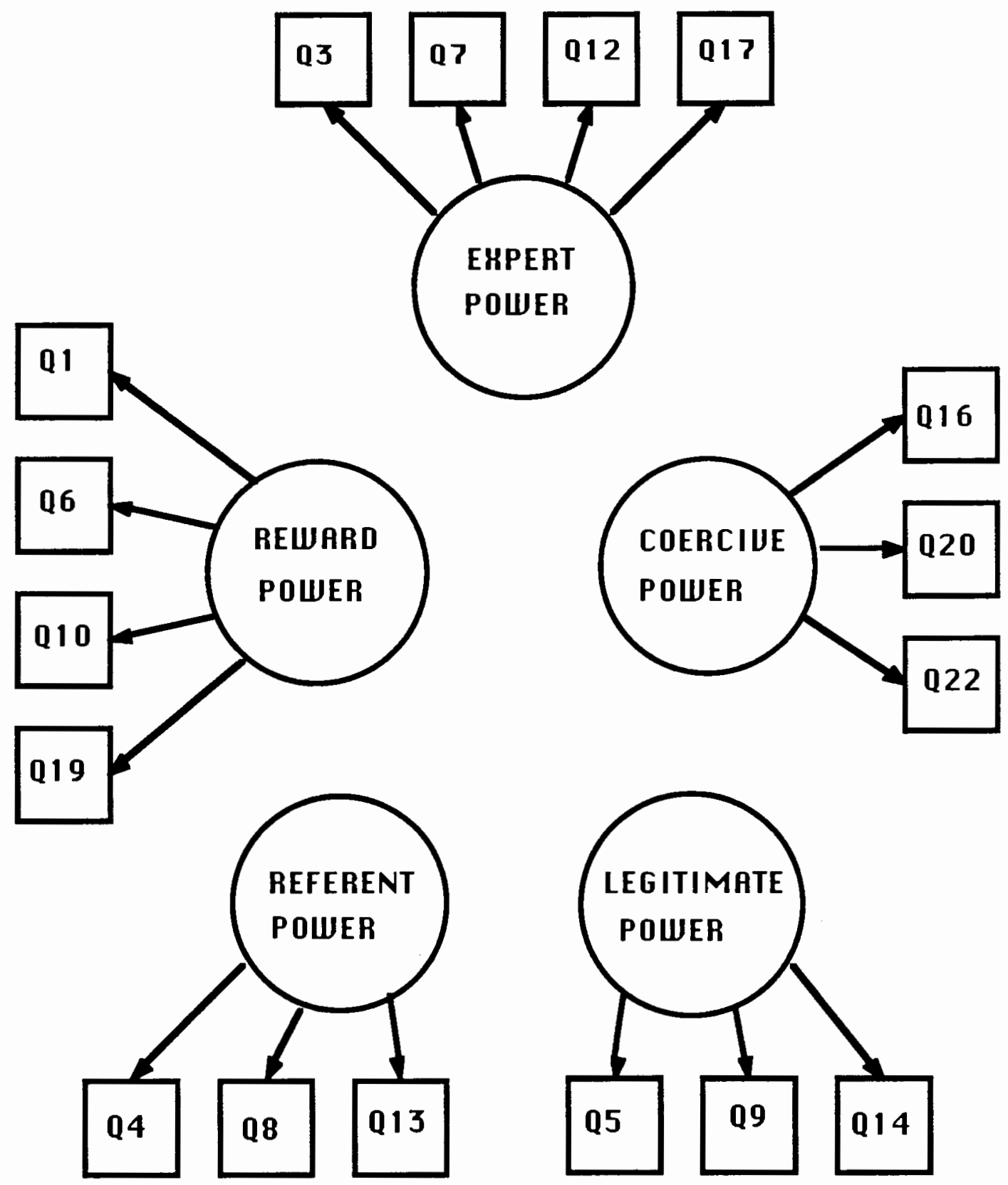

Figure 1. Path diagram of the hypothesized French \& Raven (1959) model of social power. 


\section{TABLE III}

TEST STATISTICS FOR THE CONFIRMATORY FACTOR ANALYSIS OF THE FRENCH \& RAVEN (1959) MODEL

Model

Overall Measures of Fit

$\begin{array}{ccccccc}\text { Model } & & & & & & \\ & \text { chi-square } & \text { df } & \text { p } & \text { GFI } & \text { AGFI } & \text { RMR } \\ \text { Hypothesized Model } & 201.42 & 124 & .0001 & 0.82 & 0.78 & 0.12 \\ \text { Revised Orthogonal Model } & 128.85 & 82 & .001 & 0.87 & 0.83 & 0.11 \\ \text { Revised Oblique Model } & 62.30 & 72 & .79 & 0.92 & 0.89 & 0.07\end{array}$


Modifications of the hypothesized model were performed by removing items with nonsignificant $t$-values from the model. Items 7,13 , and 17 were removed and the new model was tested and the chi-square was found to be significant at the .001 level. However, the GFI and AGFI for this model show improvement in fit to a minimally acceptable level (see Table III). All remaining t-values were significant, and modification indices were minimal $(<6.50)$. Standard errors were low $(<.135)$ but there were 13 normalized residuals greater than the acceptable level of 2 .

Next, to test the independence of factors assumption, the factors were allowed to correlate so the two models could be compared. The chi-square for this model is nonsignificant and all other overall test statistics indicate good fit of the model to the data (see Table III). The chi-square difference test between the oblique model and the orthogonal model is significant ( $\mathrm{p}<.001$ ), indicating that the oblique model fits significantly better than the orthogonal model. All $t$-values in the oblique model are significant $(t>2)$, meaning all remaining paths between the measured variables an their specified latent variables are significantly different from zero. Modification indices are small $(<5)$ and standard errors are all minimal (<.188). Normalized residuals are also minimal $(<1.771)$ except for the one between item 3 and item 9 which is 2.38 . Therefore, the oblique model will be considered the final model and is represented by Figure 2. Table IV contains factor loadings for the items retained in the final model and Table $\mathrm{V}$ shows the interfactor correlations.

To summarize, the confirmatory factor analysis on the French \& Raven scale did not confirm the initial model however, after modifications a new set of subscales were found that fit the data. These 5 scales have the same interpretation and items for reward power, coercive power and legitimate power however, expert power and referent power now have 
2 items each. Lastly, the factors were found to be correlated not independent as had been hypothesized.

\section{KIPNIS, SCHMIDT, \& WILKINSON SCALE}

Figure 3 represents the first model tested as specified by the second hypothesis, which states that the downward influence portion of the Kipnis et al. (1980) scale will yield 5 factors corresponding to the influence tactics found by Kipnis et al. This model was not supported by the confirmatory factor analysis.

As shown in Table VI, a significant chi-square statistic was obtained indicating rejection of the null hypothesis that the model fits the data. All other overall measures indicate poor fit. A second model was tried in which the factors were allowed to correlate. This improved fit somewhat, but not to an acceptable level. All modification indices were less than 10 indicating that freeing more parameters would not lead to a large decline in chisquare. In addition, no justification was apparent for specifying the model in any way other than hypothesized, so no further modifications were made.

Subsequently, an exploratory factor analysis was performed on the data from the Kipnis et al. questionnaire to explore alternative explanations of the data. Principle components analysis was first performed on the data. Using the eigenvalue greater than one rule and the scree plot, it was determined that 4 factors should be retained. Seven eigenvalues were greater than one, however there was a pronounced break in the scree plot at 4 factors. Both solutions were inspected and the 4 factor solution was selected because it was most interpretable. Next, the common factor model, with iterative principle axis factoring for 4 factors and varimax rotation was performed. In addition an oblique solution using Harris-Kaiser rotation was found. The interfactor correlations indicated that the oblique solution was the most proper of the two considering the magnitude of the 
correlations. Table VII indicates the factor loadings on the 4 oblique factors and Table VIII shows the interfactor correlations.

The 4 factor model only explained $37.68 \%$ of the variance in the data and interpretation of these factors is not clear. None of the factors correspond exactly to those obtained by Kipnis et al. (1980). A rough interpretation of Factor 1 would be Persuasion. This factor contained the most diverse items of the four. Its items seemed to indicate influence through group pressure as indicated by items 12 and 32 and possibly the positive or reinforcing aspects involved as indicated by items 44 and 46 . The second factor is mostly comprised of rationality items and seems to reflect this as Kipnis et al. originally reported. Factor 3 indicates punishment comprised mostly of items from sanctions and also including other items that are punitive in nature (e.g. item 18, "demanded that he or she do what I requested" and item 39, "bawled him or her out"). Lastly, Factor 4 perhaps best called affect manipulation, comprised of items mostly dealing with the targets mood before or during the influence attempt.

To summarize, the confirmatory factor analysis on the Kipnis et al. scale did not confirm the initial model and no model was found that adequately fit the data. Further exploratory analysis yielded 4 factors with possible alternative interpretations, however, these 4 factors are distinctly different from the Kipnis et al. factors and account for $37.68 \%$ of the variance.

\section{COMBINING THE TWO SCALES}

After analyzing each model separately, the next analysis included data from both questionnaires. A canonical correlation among the composite scores of the 5 French and 


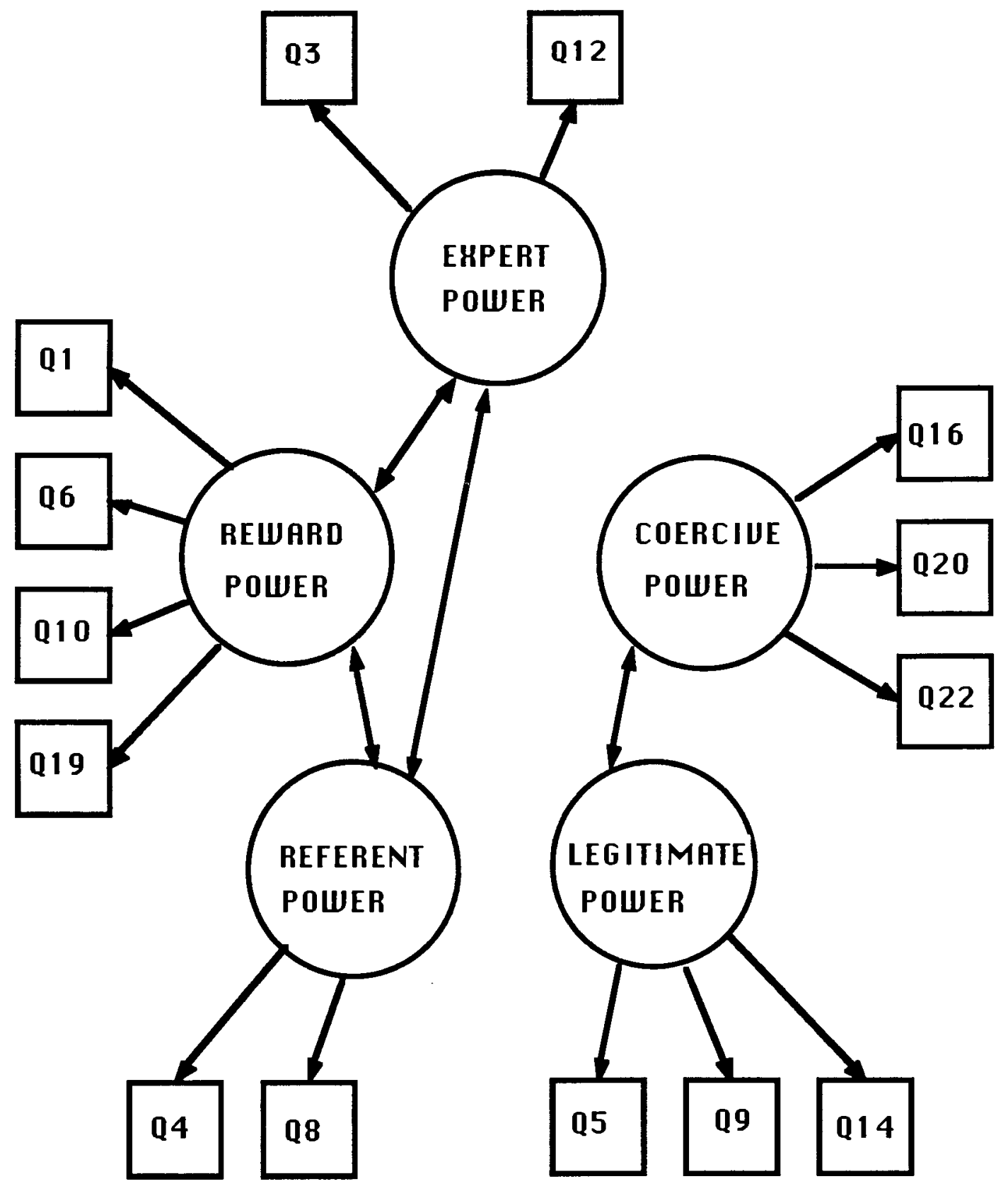

Figure 2. Path diagram of the final French \& Raven (1959) model of social power. 
TABLE IV

FACTOR LOADINGS FOR ITEMS RETAINED IN THE FINAL FRENCH \& RAVEN MODEL

$\begin{array}{lcccc}\text { Expert } & \text { Coercive } & \text { Legitimate } & \text { Referent } & \text { Reward } \\ \text { Power } & \text { Power } & \text { Power } & \text { Power } & \text { Power }\end{array}$

Item 1

Item 3 .53

Item 4 .75

Item 5

.50

Item 6

Item 8

.28

Item 9

.49

Item 10

Item 12

.56

Item 14

.60

Item 16

.64

Item 19

Item 20

.41

Item 22 
TABLE V

INTERFACTOR CORRELATIONS BETWEEN THE FRENCH \& RAVEN FACTORS

$\begin{array}{cccccc} & \text { EP } & \text { CP } & \text { LP } & \text { RFP } & \text { RWP } \\ \text { EP } & & & & & \\ \text { CP } & -.86 & & & & \\ \text { LP } & -.45 & 2.43 & & & \\ \text { RFP } & 2.92 & 1.18 & -.15 & & \\ \text { RWP } & 5.82 & .87 & -.50 & 2.61 & \end{array}$

(note: greater than or equal to 2.00 in magnitude considered significant in LISREL) 


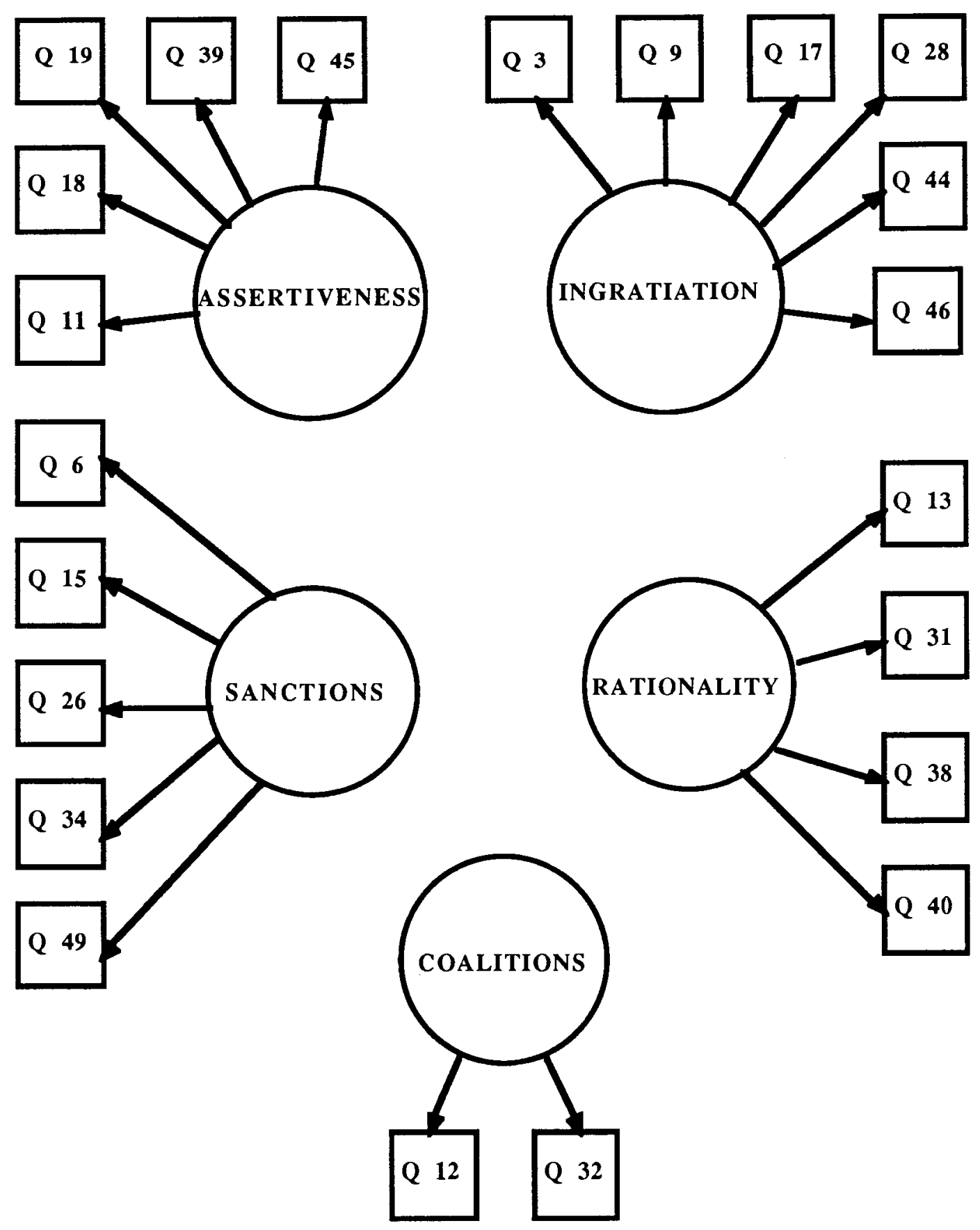

Figure 3. Path diagram of the hypothesized Kipnis, Schmidt, and Wilkinson (1980) model of social power. 


\section{TABLE VI}

TEST STATISTICS FOR THE CONFIRMATORY FACTOR ANALYSIS OF THE KIPNIS ET. AL. (1980) MODEL

Overall Measures of Fit

Model

$$
\text { chi-square df } \quad \mathrm{p} \quad \text { GFI } \quad \text { AGFI RMR }
$$

Hypothesized Model

$$
\begin{array}{llllll}
450.78 & 214 & .0001 & 0.75 & 0.70 & 0.20
\end{array}
$$

Final Oblique Model

$\begin{array}{llllll}325.21 & 204 & .0001 & 0.80 & 0.75 & 0.13\end{array}$


TABLE VII

FACTOR LOADINGS FOR THE EXPLORATORY FACTOR ANALYSIS OF THE KIPNIS ET AL. QUESTIONNAIRE DATA

$\begin{array}{cccccc}\text { Item } & \text { Factor } 1 & \text { Factor } 2 & \text { Factor 3 } & \text { Factor } 4 & \text { Communality } \\ 3 . & .19 & .12 & .06 & .44 & .20 \\ 6 . & .13 & .01 & .65 & .07 & .45 \\ 9 . & .17 & .11 & -.03 & .37 & .14 \\ 11 . & .32 & .41 & .30 & -.08 & .33 \\ 12 . & .80 & .23 & .20 & .23 & .66 \\ 13 . & .27 & .65 & .13 & .30 & .43 \\ 15 . & -.11 & .16 & .45 & -.14 & .30 \\ 17 . & .35 & .38 & .22 & .61 & .45 \\ 18 . & .16 & -.01 & .54 & -.17 & .34 \\ 19 . & .22 & .30 & .35 & -.07 & .24 \\ 26 . & .27 & .12 & .77 & .07 & .61 \\ 28 . & .24 & .24 & .01 & .70 & .49 \\ 31 . & .15 & .58 & -.08 & .21 & .36 \\ 32 . & .57 & .21 & .00 & .36 & .36 \\ 34 . & .14 & .13 & .65 & .05 & .43 \\ 38 . & .18 & .73 & .03 & .25 & .56 \\ 39 . & .01 & -.07 & .60 & -.04 & .39 \\ 40 . & .49 & .52 & -.13 & .21 & .42 \\ 44 . & .49 & .47 & -.06 & .47 & .40 \\ 45 . & -.05 & -.23 & .33 & -.34 & .25 \\ 46 . & .42 & .24 & .18 & .24 & .20 \\ 49 . & .05 & .16 & .52 & .12 & .31\end{array}$

Total common variance $\quad 27.69 \% \quad 30.82 \% \quad 36.93 \% \quad 25.25 \%$ explained by each factor.

Proportion of common $\quad 14.85 \% \quad 19.59 \% \quad 34.60 \% \quad 15.37 \%$ variance explained uniquely by each factor.

Total variance explained by the model $=37.68 \%$ 
TABLE VIII

FACTOR INTERCORRELATIONS OF THE KIPNIS ET AL. EXPLORATORY FACTOR ANALYSIS

$\begin{array}{lcccc} & \text { Factor 1 } & \text { Factor 2 } & \text { Factor 3 } & \text { Factor 4 } \\ \text { Factor } 1 & 1.00 & & & \\ \text { Factor } 2 & .40 & 1.00 & & \\ \text { Factor 3 } & .17 & .10 & 1.00 & \\ \text { Factor } 4 & .38 & .35 & -.02 & 1.00\end{array}$


Raven (1959) subscales and the composite scores of the 5 Kipnis et al. (1980) subscales was performed. Items used to comupte the composite scores for the French \& Raven constructs were the items derived from the final confirmatory model, the items used for the Kipnis et al. constructs were those originally proposed in the initial model. Wilks' lambda reached significance $(\mathrm{F}(25,366)=2.55, \mathrm{p}<.0001)$. As Table IX indicates, $\mathrm{F}$ tests revealed the first two canonical correlations were significant. The first canonical correlation accounts for $25 \%$ of the variance between the two sets of subscales and the second accounts for $19 \%$ of the variance.

Table $\mathrm{X}$ shows the standardized canonical coefficients for the two significant canonical variates. The highest standardized coefficient for the power base subscales on the first variate is Coercive Power (.819). The highest standardized coefficient on the influence tactic subscales on the first variate is Assertion (.755). In considering the items on the Assertion subscale, it is clear that some of them could be considered coercive in nature. For example, item 39 on the Kipnis et al. scale is "Bawled him or her out". This could be interpreted as coercive in nature. The first canonical correlation seems to reflect what the French \& Raven and Kipnis et al. subscales measure in common in terms of coercive or punitive power or tactics.

On the second pair of variates, Expert Power (.547) and Reward Power (.345) are among the higher standardized coefficients for the power base subscales. Legitimate Power (-.466) is strongly negatively related on this variate. Clearly, Rationality (.945) has the largest coefficient among the influence tactics on this variate and Assertion (-.434) is strongly negatively related. Expert Power and Rationality could be interpreted as similar constructs. For example, "Used logic to convince him or her" and "Explained the reasons for my request" (items 13 and 31 respectively on the Kipnis et al. scale) might be the types of behaviors an expert might use when conveying his/her argument or giving orders. 
TABLE IX

RELATIONSHIP BETWEEN THE FRENCH \& RAVEN (1959) AND KIPNIS ET AL. (1980) CONSTRUCTS

$\begin{array}{ccccc}\begin{array}{c}\text { Canonical } \\ \text { Correlation }\end{array} & \begin{array}{c}\text { Squared } \\ \text { Canonical } \\ \text { Correlation }\end{array} & \mathrm{F} & \mathrm{df} & \mathrm{p} \\ .50 & .25 & 2.55 & (25,366) & .0001 \\ .43 & .19^{*} & 2.03 & (16,303) & .01\end{array}$

* value not exact due to rounding error 
TABLE X

STANDARDIZED CANONICAL COEFFICIENTS FOR EACH SCALE

$\begin{array}{lcc} & \text { V1 } & \text { V2 } \\ \text { Coercive Power } & .819 & -.185 \\ \text { Reward Power } & .467 & .345 \\ \text { Expert Power } & .152 & .547 \\ \text { Legitimate Power } & .121 & -.466 \\ \text { Referent Power } & .010 & .178 \\ & & \\ & \mathrm{~W} 1 & \mathrm{~W} 2 \\ \text { Assertiveness } & .775 & -.434 \\ \text { Rationality } & .306 & .945 \\ \text { Coalitions } & .281 & -.134 \\ \text { Sanctions } & .175 & .170 \\ \text { Ingratiation } & -.074 & .046\end{array}$


Therefore, this canonical correlation could be seen as reflecting what the 2 questionnaires measure in common in terms of expert or logical power or tactics.

An exploratory factor analysis was performed on the pooled data from both measurement instruments to explore the possible way that all the items may group together. The principle components analysis and the scree plot indicated no clear number of factors decision. The results indicate that the factor model probably does not apply to the combined data set. It is important to note that the sample size for an exploratory factor analysis on the pooled data is quite low $(\mathrm{N}=108)$ compared to the minimum required $(\mathrm{N}=410)$.

To improve the variable to subjects ratio, higher order exploratory factor analysis was performed on the sub-scale composite scores of the 2 questionnaires. The same procedure was performed for this exploratory factor analysis as was explained previously. This led to a 2 factor, orthogonal solution (note: $r=.06$ between factors when they were allowed to correlate), which explaines $29 \%$ of the variance in the data. Table XI shows the factor loadings for the two higher order factors. Coercive Power, Assertion, and Sanctions load on Factor 1 which will be called Negative Power. Expert Power, Reward Power, Ingratiation, and Rationality load onto Factor 2 which will be called Positive Power. These results suggest that the questionnaires of the two theoretical perspectives, bases of social power and social influence tactics, explored in this paper measure to some extent a common psychological space of the respondents. Positive power may include the power bases and behavioral tactics that are preferred or possibly perceived as good by subjects. Negative power may be those power bases and behavioral tactics perceived as less desirable or bad by respondents. The fact that these factors are not correlated to any meaningful level supports that interpretation. 
TABLE XI

FACTOR LOADINGS FOR THE HIGHER ORDER EXPLORATORY FACTOR ANALYSIS

\section{Factor 1 Factor 2 Communality}

Power Bases

$\begin{array}{lccc}\text { Reward Power } & .09 & .46 & .22 \\ \text { Legitimate Power } & .26 & -.12 & .08 \\ \text { Referent Power } & .05 & .29 & .09 \\ \text { Expert Power } & -.28 & .47 & .30 \\ \text { Coercive Power } & .57 & .04 & .33\end{array}$

Influence Tactics

$\begin{array}{lrrl}\text { Ingratiation } & .05 & .46 & .22 \\ \text { Rationality } & -.14 & .70 & .52 \\ \text { Assertiveness } & .78 & .17 & .64 \\ \text { Sanctions } & .60 & .14 & .38 \\ \text { Coalitions } & .18 & .33 & .14\end{array}$

Percent of common variance $51.68 \% \quad 48.32 \%$ explained for by each factor.

Percent of total variance $\quad 15.05 \% \quad 14.07 \%$ explained for by each factor.

Total variance explained by the model $=29.12 \%$ 


\section{DISCUSSION}

A revised, meaningful model for the French \& Raven (1959) bases of social power was reached through confirmatory factor analysis. The revised scale differs from the Frost $\&$ Stahelski (1988) scale in two ways. First, the scale was reduced by 3 items. Second, the factors were found to be correlated. Clearly, the results of these analyses in addition to the previously reported exploratory factor analysis of the scale by Frost \& Stahelski (1988) are strong evidence that the 5 bases of social power, as proposed by French \& Raven (1959), are in fact meaningful constructs. These results are evidence that the quagmire of differing results from the study of French $\&$ Raven in the field as documented by Podsakoff $\&$ Schriesheim (1985) may in fact be due to the shortcomings of past instrumentation used and not due to shortcomings of the theory.

The lack of content validity of prior measurement instruments described by Podsakoff \& Schreishiem (1985) was addressed in this study by using multi-item scales while at the same time broadening operationalization of the constructs. In addition, wording of the items was done in such a way as to be specific enough to minimize interpretation by respondents. Another improvement over earlier scales was to use a behavioral referent rather than an attributional referent in the subjects responses. This asks subjects to report their behavioral frequencies rather than ask them to attribute the reasons for their subordinate's compliance which, as discussed before, can be biased by social desirability and memory limitations.

Although future research should seek to replicate the findings using this scale to increase confidence in its validity, expanded use of such a scale in studying leader behavior would lead to more consistent findings in the relationship of the use of power by leaders 
and subordinate, group, and organizational outcomes. This in turn would lead to more useful understanding of leader behavior for the organizational researcher and practitioner.

Future research should also explore the nature of the relationship between the power constructs in more depth. French \& Raven (1959) themselves wrote about possible relationships between the factors in their original article. They discuss situations where the possession of one form of power by the leader can affect the outcomes or perceptions of subordinates when the leader uses other forms of power. For example, in discussing Legitimate Power they wrote;

We have used the term legitimate not only as a basis for the power of an agent, but also to describe the general behaviors of a person. Thus, the individual $P$ may also consider the legitimacy of the attempts to use other types of power by $\mathrm{O}$. In certain cases, $\mathrm{P}$ will consider that $\mathrm{O}$ has a legitimate right to threaten punishment for nonconformity; in other cases, such use of coercion would not be seen as legitimate. $\mathrm{P}$ might change in response to coercive power of $\mathrm{O}$, but it will make a considerable difference in his attitude and conformity if $\mathrm{O}$ is not seen as having a legitimate right to use such coercion (p. 266).

The evidence in this paper shows that the power bases are separate, although not necessarily independent, constructs. One could look at how the use of one form of power can affect the effectiveness of using other power bases as well as differential effects on subordinate outcomes.

The results of the Kipnis, Schmidt, \& Wilkinson (1985) scale analysis did not support the 5 hypothesized influence tactics. The subsequent exploratory factor analysis did not lead to a meaningful result. It is difficult to assess why this occurred. The influence tactic factors are often explained by the items that comprise them. This lack of theoretical background for the influence tactics leaves little to base explanations on. It is possible that the inductive nature of the study by Kipnis et al. (1980) led to results that were meaningful only to the specific sample studied.

In an effort to explore relationships between the two systems, a canonical correlation was performed and lead to a significant connection between the two models. Coercive 
power and expert power correlated on the same dimensions as assertiveness and rationality respectively. Studying the first significant canonical dimension, it makes sense intuitively that influence tactics such as "Bawled him or her out" and "Demanded that he or she do what I requested" would be related to the concept of coercive power. Likewise on the second significant canonical dimension, "Used logic to convince him or her" and "Presented him or her with information in support of my point of view" seem congruent with the concept of expert power. Other relationships between the influence tactics and the power bases seem logical, however there was only strong evidence for these dimensions.

The relationship of all 5 power base composite scores and all 5 influence tactic composite scores were analyzed simultaneously with higher order exploratory factor analysis, allowing the constructs to group the way the data dictates without imposing groupings as is the case with canonical correlation where the 2 groups of constructs were grouped according to each theory. The results indicated that the constructs did not load on separate factors as might be predicted (i.e., power bases on one factor and influence tactics on the other), but grouped in a more complex fashion. On Factor 1 called Negative Power, the scales Coercive Power, Assertiveness, and Sanctions all loaded at .60 or above. Although not as highly, Legitimate Power tended to load on this factor (.26) while loading low on Factor $2(-.12)$. Perhaps the power and influence constructs on this factor are seen as undesirable or unpreferred by respondents. In Podsakoff \& Schriesheim's (1985) summary there is some evidence that Coercive Power could be undesirable as indicated by negative relation to outcome variables such as job satisfaction. Due to the connection already mentioned between Coercive Power and Sanctions and Assertiveness would logically fall into this category also. Legitimate power weakly loaded on this factor perhaps because it is perceived as more neutral than those constructs loading highly on this factor.

The constructs loading on Factor 2, or Positive Power, at .46 or above include Reward 
Power, Expert Power, Ingratiation, and Rationality. Weaker loadings include Referent Power at .29 and Coalitions at .33. Certainly these forms of influence could be perceived as more desirable by subjects because they rely upon logical, relationship, or less confrontive strategies for influence. As indicated in Podsakoff \& Schriesheim (1985) there is some evidence for relationships between Reward Power and positive outcome variables such as supervisory satisfaction and performance. Also, relationships between Expert Power and outcomes such as performance, job satisfaction and role clarity can be found. It should be restated here that all of these relationships between the power bases and outcomes should be considered tentative because of the shortcomings of the methodology used to arrive at them. For instance, one can also find in Podsakoff \& Schriesheim relationships opposite of some of the examples used in discussing the higher order factors.

The results of the higher order analysis indicate that perhaps subjects psychologically categorize power and influence exerted over them into two categories, those that they prefer or will accept and those they do not prefer and would rather do without. Or perhaps the constructs on a factor are simply used as a package. In other words, if one uses a power or tactic from one factor often, they are probably using the other power bases and tactics on that factor more frequently than the bases or tactics on the other factor. This is something that could be tested in the future. This not only helps account for the strong relationships often found between power bases but in future research could prove important in the furthering of theory on leader effectiveness depending upon the dimension of influence (negative or positive) used in different situations. It should be emphasized that the amount of variance explained in the combined analyses is not large. Yet given the fact that the Kipnis et al. constructs were not confirmed, it is interesting to find meaningful (if perhaps weak in this paper) effects when analyzing them with the power constructs.

Not many would argue that influence tactics in some form occur in the workplace at some level, even though the Kipnis et al. results were not replicated in this study. Perhaps 
there are other ways to look at influence other than its genesis from the latent constructs proposed by Kipnis et al.. And perhaps it is a mistake to research a power theory and influence theory totally independently as is most often the case. It is not clear yet how power and influence are similar or different, but consider that influence tactics are simply behaviors. It seems that the items on the French \& Raven scale are also behaviors. For example from the French \& Raven scale, "Advise and Assist them" (item 3), and "Give them high performance ratings" (item 10) could be considered behavioral tactics just as much as "Used logic to convince him or her" (item13) and "Promised (or gave) a salary increase" (item15). Perhaps the influence tactics are, at least to some extent, the behaviors that measure the degree of power a leader has. This would be true for the behavioral items on both scales. If you consider the canonical and higher order factor analyses in this paper, clearly there is some connection or overlap between the two theoretical perspectives. Perhaps the influence tactics are measuring the power bases of French \& Raven in addition to some other content that may be meaningful.

A possible way of researching the connection between power and influence in depth might be to use the power bases as predictor variables and the influence tactics as criterion variables. Perhaps different levels or combinations of power bases would lead to differential use of influence tactics. For example, increases in Expert Power may lead to an increase in the frequency of use of items on Expert Power and some or all of the items on Rationality. Or perhaps use of latent variable modeling that loaded the influence tactics as manifest variables onto the power bases as latent constructs might show that the power bases are latent and that influence tactics are measurable behavioral variables. Certainly the French \& Raven scale in this article does not include an exhaustive list of the possible behaviors that could load onto the factors, if it did, it wouldn't be a practical scale.

One insight into how the power bases themselves may relate to each other might be 
found in a article by Imai (1989) who studied target's perceptions of the power of certain influencing agents in their lives and the target's perception of being influenced by them. Students, housewives, and businesspersons were asked to rate mother, father, teacher and friend (for students), mother, father, and husband (for housewives), and junior coworkers, senior coworkers, colleague, and wife (for business persons) in terms of their social power as perceived by respondents and respondents' perception of being influenced by them.

Imai considered people meeting for the first time to perform a task engage in a social interaction where rewards and punishments are exchanged in the form of money, physical objects, praise, physical attack, and information. These are what Imai calls the basics of social interactions or Primary Power and include reward power, coercive power (punishment), and expert power (information). After interacting awhile, the person contributing the least amount of resources to the task may come to believe the person contributing more has a right to influence them and/or wants to be more like that person. These are what Imai calls Secondary Powers, formed after several social interactions, and include legitimate and referent powers. Based on these social exchanges in interpersonal relationships, path models were created that hypothesized the relationships between the perceived bases of social power and the perception of being influenced stating that the path coefficients from Primary to Secondary powers and the paths from Secondary Powers to the perception of being would be significant.

Using multiple regression to test these paths, Imai found overall support that perception of a specific social power affected perception of another social power or perception of being influenced. Almost all paths from Primary to Secondary powers were significant. Legitimate power was significantly related to perception of being influenced in every interpersonal relationship. Coercive power was related to the perception of being influenced in many of the relationships. Referent power was related to social position of the influencing agent. Those agents with high status relative to respondents did not have 
significant path loadings from referent power however, those agents with equal or lower status than target did have significant path loadings from referent power. Results did vary as a function of the specific interpersonal relationship.

These findings are very interesting, but the results should be considered cautiously, especially with respect to the present paper. Imai (1989) created the scales to measure perceived social power and perception of being influenced and attained moderately high alpha coefficients and moderately high test-retest coefficients. Content validity was assessed by judges assigning items to the social powers and high ratios of correspondence between raters was found. However, there are several reasons to be cautious in relating Imai's findings to this paper. The scale suffers from several of the shortcomings covered at the beginning of this paper. The scales seem suceptable to the social desirability response bias outlined by Podsakoff and Schriesheim (1985). When asking whether the respondent's mother "abuses me psychologically or physically" (coercive power item) for example, this raises the question are people responding with what really happens or the socially desirable answer. In addition the items are very general and the interpretation necessary by respondents when answering brings the content validity into question. The scale measuring perceived influence also seems suseptable to social desirability bias. For example, one item asks, "when I have an opinion different from X's (influencing agent), I often change my opinion in such a way as to be consistent with X's". Clearly, social desirability can come into play, and Podsakoff $\&$ Schriesheim (1985) warn, social desirability on the power scale and criterion measure can lead to spurious relationships.

A body of literature parallel to that of this paper, Frost \& Stahelski (1988), and Stahelski, Frost \& Patch (1989) includes another systematic effort to create a psychometrically sound measurement instrument for measuring the French \& Raven constructs and exploring the nature of the relationship between these social power constructs and the social influence tactics of Kipnis et al. (1980). Hinkin \& Schriesheim 
(1989) developed new theoretical definitions of the power bases from which to create a new scale of measurement (note: this study was published after completion of the data analyses reported in this paper). Their scale also addresses the shortcomings pointed out by Podsakoff $\&$ Schriesheim (1985). They administered a list of generated items to three samples for scale development. Satisfaction and commitment measures were also administered. Exploratory and confirmatory factor analyses were performed on the data. Analysis of the first sample reduced their initial 42 item scale down to 20 items ( 4 items per power base). Using confirmatory factor analysis they attained a .90 GFI, .86 AGFI, and $.06 \mathrm{RMR}$. They sought to replicate the results of the factor analysis from the first sample on the second and third samples. The confirmatory factor analysis on the second sample supported the a priori structure from the first sample well. The confirmatory factor analysis results from the third sample were weaker than the second sample having quite a few cross-loadings and slightly lower GFI and AGFI levels, but still provided support for the factor structure. The power base measures were then related to satisfaction and commitment measures and discussed in relation to past empirical relationships between these constructs.

It is worth pointing out some of the similarities and differences between the scale developed in this paper and the one developed by Hinkin \& Schriesheim (1989). The similarities include the fact that both addressed many of the major methodological shortcomings of scales used in the past. Both gave attention to content validity through use of multi-item scales (avoiding rank order), use of a behavioral referent, and more specific items reducing respondent's interpretation that could lead to unwanted variation. Among the differences are that subjects in this paper were the supervisors and subjects in the Hinkin \& Schriesheim paper were subordinates. Hinkin \& Schriesheim measured perceived potential power of their supervisor (respondents answered the question to what 
extent they agreed that their supervisor could do this to them) and in this article the selfreport of actual behaviors was measured (respondents asked to report how often they actually use each behavior to influence their subordinates). Yet, most importantly, even with the differences mentioned and all the possible pros and cons, strengths and weaknesses that could be argued (endlessly as most often occurs) concerning either approach, the biggest similarity of all still occurred - in both cases through analyzing the data with LISREL, both models fit the data. In other words, despite differences in whether the respondent is the target or the agent and differences in scale items, both scales lead to a solution supporting the latent constructs as proposed by French \& Raven (1959). Clearly, this convergent validity must be seen as evidence that past problems in studying power were due to instrumentation and that the power base constructs are in fact meaningful, can be adequately measured, and eventually related to other important organizational variables.

Another article by Schriesheim \& Hinkin (1990) attempts to improve the measurement scale of the Kipnis et al. (1980) social influence tactics. They discuss the influence tactics in more detail offering an in depth critique and reanalysis with the goal of improving the measurement of the all the influence tactics. They write "because the Kipnis et al. measures are important, we undertook four studies, both to explore the quality of the Kipnis et al. scales and to improve on them so that they may be used in future research with increased confidence." (p. 248)

Although the critique of the influence tactics is general to all of the work of Kipnis et al. (1980), the scales explored and improved were the upward influence tactics, not the downward tactics used in this paper. They also were unable to replicate Kipnis et al.'s results but were able to create an 18 item scale including 15 original items plus three new ones they wrote that, through exploratory and confirmatory factor analysis, that supported a 6 factor solution (they combine two of the factors Kipnis et al. originally proposed were upward influence dimensions into one factor). 
The final article in the parallel body of literature is the article of Hinkin \& Schriesheim (1990). In this article they explore the nature of the relationship between the power bases, as measured by their new scale, and the influence tactics for downward influence. They note that power and influence are often treated as synonymous but the "empirical literature relating power and influence as distinct constructs is virtually non-existent" (p. 222). They take the position that followers attribute power of the leader from perceived behavioral cues (influence tactics) of the leader. Their goal was to show that these are separate constructs and then to link them together to explore relationships. Since their scale measures perceptions of subordinates, the instructions for the Kipnis et al. instrument had to be modified from "How I influence my subordinates", to "How my superior influences me". They didn't find support for the 7 influence found by Kipnis et al. They ultimately reduced the number of items to 24, and combine Upward Appeal and Sanctions onto one factor. They presented arguments for some specific correlations between the influence tactics and the power bases, some of which occurred. Through confirmatory factor analysis they found "support for perceptual distinctiveness between the constructs of power and influence, and although they are related constructs, respondents were able to distinguish between influence behaviors and attributions of power." (p.233) They conclude by reviewing the hypothesized correlations between power and influence factors that occurred. They argue that it is important to know which tactics are correlated with expert and referent power because these powers are seen as qualities of a "good" leader.

The main difference between the Hinkin \& Schriesheim (1990) study and the present one is that their factor analysis does not support the results found in the higher order analysis in this study. Their confirmatory factor analysis of the combined data from their scales for measuring the French \& Raven constructs and their scale for measuring the Kipnis et al. constructs yielded 6 factors, none of which had both power and influence constructs loading on it. However, it is not surprising that Hinkin \& Schiesheim's factor 
analysis of the French \& Raven and Kipnis et al. constructs results are not congruent with this study. They used 7 of the original 8 influence tactics factors and only 5 were reported to be associated with downward influence (Kipnis et al., 1980, p. 447). They do not explain why they include non-downward influence factors when the study uses the subordinate as the target of influence. In addition, their factor analysis was on the raw data, they did not take the next step and perform a higher order factor analysis on composite scores. The results of such an analysis with composite scores from their data may in fact support the findings of the higher order analysis in this study.

In conclusion, the evidence that the French \& Raven (1959) bases of social power are meaningful, and probably useful, constructs as shown in this and other empirical studies (Frost \& Stahelski, 1988; Frost, Stahelski, \& Patch, 1989; Hinkin \& Schriesheim, 1989; Hinkin \& Schriesheim, 1990) is mounting. In addition to the other suggestions for future study already mentioned, a study could be done comparing targets' reports of their leader's behavior (using the Frost \& Stahelski scale in this paper and/or the Hinkin \& Schriesheim (1989) scale) with agents' self report of their own behavior within the same workgroups. This would address the main difference between this study and Hinkin \& Schriesheim (1989) that raises the question of whether differences exist between leader self report and subordinate perception of the leader's behavior. 


\section{REFERENCES}

Abdalla, I. A. H. (1987). Predictors of the effectiveness of supervisory social power. Human Relations, 40(11), 721-740.

Bachman, J. G., Smith, C. G., \& Slesinger, J. A. (1966). Control, performance, and satisfaction: Ananalysis of structural and individual effects. Journal of Personality and Social Psychology, 4, 127-136.

Bachman, J. G. (1968). Faculty satisfaction and the dean's influence: An organizational study of twelve liberal arts colleges. Joumal of Applied Psychology, 52(1), 55-61.

Burke, R. J., \& Wilcox, D. S. (1971). Bases of supervisory power and subordinate job satisfactions. Canadian Journal of Behavioral Sciences, 3, 183-193.

Dieterly, D., \& Schneider, B. (1974). The effect of organizational environment on perceived power and climate: A laboratory study. Organizational Behavior and Human Performance, 11, 316-337.

Dovidio, J. F., Ellyson, S. L., Keating, C. F., Heltman, K., \& Brown, C. E. (1988). The relationship of social power to visual displays of dominance between men and women. Journal of Personality and Social Psychology, 54(2), 233-242.

Fiorelli, J. S. (1988). Power in work groups: Team member's perspectives. Human Relations, $\underline{41}(1), 1-12$.

French, J. R. P., Jr., \& Raven, B. H. (1959). The bases of social power. In D. Cartwright (Ed.), Studies in Social Power (pp. 150-167). Ann Arbor: University of Michigan Press.

Frost, D. E., \& Stahelski, A. J. (1988). The systematic measurement of French and Raven's bases of social power in workgroups. Journal of Applied Social Psychology, 18(5), 375-389.

Hinkin, T. R., \& Schriesheim, C. A. (1989). Development and application of new scales to measure the French and Raven (1959) bases of social power. Journal of Applied Psychology 74(4), 561-567.

Hinkin, T. R., \& Schriesheim, C. A. (1990). Relationships between subordinate perceptions of supervisor influence tactics and attributed bases of supervisory power. Human Relations. 43(3), 221-237.

Imai, Y. (1989). The relationship between perceived social power and the perception of being influenced. Japanese Psychological Research, 31(3), 97-107. 
Joreskog, K. G., \& Sorbom, D. (1986). LISREL: Analysis of linear structural relationships by the method of maximum likelihood. (Version VI) Scientific Software Inc: Mooresville: Indiana.

Kipnis, D., Schmidt, S. M., \& Wilkinson, I. (1980). Intraorganizational influence tactics: Explorations in getting one's way. Journal of Applied Psychology, 65(4), 440-452.

McDaniel, S. W., Parasuraman, A., \& Futrell, C. M. (1985). Social power bases of marketing executives: The relationship with organizational climate. Journal of Business Research, 13, 77-85.

Offermann, L. R., \& Schrier, P. E. (1985). Social influence strategies: The impact of sex, role, and attitudes toward power. Personality and Social Psychology Bulletin, 11(3), 286-300.

Podsakoff, P. M., \& Schriesheim, C. A. (1985). Field studies of French and Raven's bases of power: Critique, reanalysis, and suggestions for future research. Psychological Bulletin, 97(3), 387-411.

Rahim, M. A. (1986). Some psychometric properties of two measures of French and Raven bases of power. Journal of Psychology: Interdisciplinary and Applied, $120(5), 465-472$.

Schriesheim, C. A., \& Hinkin, T. R. (1990). Influence tactics used by subordinates: A theoretical and empirical analysis and refinement of the Kipnis, Schmidt, and Wilkinson subscales. Journal of Applied Psychology 75(3), 246-257.

Shaw, J. I., \& Condelli, L. (1986). . Effects of compliance outcome and basis of power on the powerholder-target relationship. Personality and Social Psychology Bulletin, 12(2), 236-246.

Spekman, R. E. (1979). Influence and information: An exploratory investigation of the boundary role person's basis of power. Academy of Management Journal, 22(1), 104-117.

Stahelski, A. J., Frost, D. E., \& Patch, M. E. (1989). Use of socially dependent bases of power: French and Raven's theory applied to workgroup leadership. Journal of Applied Social Psychology, 19(4), 283-297.

Student, K. R. (1968). Supervisory influence and workgroup performance. Journal of Applied Psychology, 52, 188-194.

Szilagyi, A. D. (1980). Causal inferences between leader reward behaviour and subordinate performance, absenteeism, and work satisfaction. Journal of Occupational Psychology, 53, 195-204.

Thamhain, H. J., \& Gemmill, G. R. (1974). Influence styles of project managers: Some project performance correlates. Academy of Management Journal, 17, 216-224.

Wexley, K. N., \& Snell, S. A. (1987). Managerial power: A neglected aspect of the performance appraisal interview. Journal of Business Research, 15, 45-54. 